\title{
Understanding Tourists' Perceptions of Eastern Indonesia
}

\author{
*Darmianti Razak, " Fajrin Satria Dwi Kesumah \\ * Adelaide Business School, The University of Adelaide, 10 Pulteney St, Adelaide SA \\ 5005, Australia \\ * Department of Sharia Banking, University of Muhammadiyah Lampung, \\ Jl. ZA. Pagar Alam, Labuhan Ratu, Kec. Kedaton, Lampung 35132, Indonesia
}

Corresponding author: kesumah.fajrin@uml.ac.id

\section{ABSTRACT}

This paper examines tourists' perceptions of Eastern Indonesia through comparisons with foreign visitors' who have been to Indonesia, specifically Eastern Indonesia, and those who have never been to Indonesia. The aims of this study are to assess what foreign tourists perceive about Eastern Indonesia and elaborate the differences between the perceptions of visitors and non-visitors. The comparison of the visitor and non-visitor perceptions is important in order to understand Eastern Indonesia more deeply. This qualitative research uses focus group interviews to assess the perceptions of Eastern Indonesia. The perceptions from different participants came from different nationalities. In Group 1, two participants came from China, two Saudi Arabians, and one Bangladeshi. The four participants in Group 2 came from Australia. All of participants were students. The results indicate that tourists who have never been to Indonesia perceive Eastern Indonesia by comparing their experiences to other places that they have visited. From those experiences, they construct a positive image of Eastern Indonesia and as a result, indicate a willingness to visit Eastern Indonesia. All Australian participants had been to Indonesia and shared a positive image of Eastern Indonesia as well as of other places in Indonesia. However, while participants' perceptions in Group 2 were positive, they also imply some ideas for the improvement regarding tourism development in Eastern Indonesia. Apart from that, all participants showed an intention to revisit and explore more places in Eastern Indonesia in the near future

Keywords:

Foreign tourist, Perceptions, Destination image, Eastern Indonesia. 


\section{INTRODUCTION}

The number of foreign tourist arrivals in Indonesia has significantly increased during recent years. The World Tourism Organisation in the Compendium of Tourism Statistics through data.worldbank.org (2018) reported that the number of foreign visitor arrivals in Indonesia surged to 1.25 billion in 2016 from 897 million in 2009 . Tourist arrivals in Indonesia estimated to be on average 783 thousand from 2011 to 2018. The report mentioned that Bali as the main destination with 443.8 thousand visitors (TradingEconomics.com, 2018). The contribution of tourism in Indonesian GDP increased gradually from 2014 to 2018. There were 11 million foreign tourists in 2016 from the initial 9 million tourists in 2014. This number is expected to reach 20 million in 2019. However, compared to neighbouring countries, Indonesia lags behind Singapore, Malaysia and Thailand (based on the ranking of the 2015 Travel and Tourism Competitiveness Report). Therefore, this is an important issue for the Indonesian economy as Indonesia is the world's largest archipelago country, with a number of tourism potentials.

\section{LITFRATURF RFVIFW}

Tourists' perceptions, experiences, and attitudes, have yet to obtain sufficient scholarly attention in marketing studies as they pertain to the issues in Eastern Indonesia. Thus, it is necessary to focus on this area since there is no previous research, which discusses tourists' perceptions of the destination image and how this image influences the positioning of some destinations in Eastern Indonesia. Nadeau et, al. (2008) underlined that observing this area of knowledge is important because it will influence tourist's decision-making processes and behaviours. A study from Shamsuddoha, M., et.al.,
(2008) regarding the tourism industry in Bangladesh reveal the top five factors that needed to support tourism development based on assessing 120 respondents. The result mentioned Communication facilities, Accommodation, Reasonable cost charges, Security, and Sightseeing are the most demandable components to attract tourists. However, this study is not too clear in describing more deeply, about how those factors influence tourist's perceptions of the destination. This study just measured the most influential factors in regards to develop a tourism industry without describing how respondents were feeling and why they perceived those factors important. Therefore, it is necessary to explore participant's impressions and beliefs through a qualitative study to gain more knowledge about how they perceive and the reason of their perception. Not everyone has the same perceptions. Therefore, image is always subjective. As such, the tourist destination image refers to perceptions of tourists in a destination. A story from participants in the current study will answer the gap of knowledge in this field.

Ivanov (2010) studied the image of Bulgaria as a tourist destination through a molecular approach to assess the destination image. The survey of this research resulted in three clusters that associated with Bulgaria as the destination. First, the term "Sunny Beach" and "Golden Sands" are reflected the foreign tourist's perception of Bulgaria. This result can be categorized as a positive image in perceiving the destination. Second, is about tourist's perception in relation to political and economic issues of the destination. Third, the other term appeared to illustrate respondents' perception of Bulgaria, "Mountain". 
The way people perceive a certain place influences their decision to travel and their satisfaction degree which based on their experiences when traveling to the destination (Cherifi, 2014). In fact, a destination image is the perception of tourists in the way they differentiate destinations from each other and is a fundamental and influential element of tourists' decision process.

In addition, Gartner (1993) added that destination images are developed by three hierarchically interrelated components: cognitive, affective, and conative. For Embacher and Buttle (1989) and Baloglu and McCleary (1999), image comprises both cognitive and evaluative components. The cognitive (or designative) aspect refers to knowledge about a place. While the affective aspects are associated with feelings from evaluation process. However, the other researchers also added the conative element. The conative component is related to the behavioural intentions regarding the destination (Urbonavicius, Dikcius \& Navickaite, 2011). On the other hand, Utama (2015) includes the push factors and the pull factors in their study. They expressed the push factors driving motivation whereas the pull factors can described as the main attractions of the destination.

In summary, consumer perception and motivation determines the attitude of the tourists and will help marketers to design a successful marketing strategy. Destinations marketing should also lead the tourism impact optimisation and the maximisation of benefits for the region (region refers to the tourists' destination). Despite the importance of this research line, there is still a lack of conceptual framework around destination image as identified in existing research. Therefore, the current research will provide a conceptual framework to illustrate the structure of the research topic.

\section{IMETHOD}

Through this study, the authors consider that every tourist destination can maximise their potential to obtain more economic benefits for all related parties. Moreover, some questions will be constructed as the foundation of this research.

RQ 1: To what extent do foreign tourists know about Eastern Indonesia?

RQ2: What are the determinant factors that influence tourists' willingness to travel abroad and particularly Eastern Indonesia?

RQ 3: How do International tourists perceive Eastern Indonesia based on their experiences?

RQ 4: How do International tourists perceive Eastern Indonesia based on what they heard from others (Friends, Families, Relatives, and Online sources)?

The conceptual framework (Figure 1) illustrated the alternative perceptions that may perceive as the common impressions that come from tourists' point of view to positioning the destination image. Meanwhile, the research method that will be applied to this study will take the form of a qualitative research. The purpose of conducting qualitative research in this study is to generate ideas in understanding people's behaviours and perceptions. Generally, the gap of this research is about perceptions. Perception is the most defining factor when the international tourists make decisions to travel abroad. Therefore, it is important to understand how the foreign tourists perceive Eastern Indonesia to attract them to visit some tourist attractions in this region. 


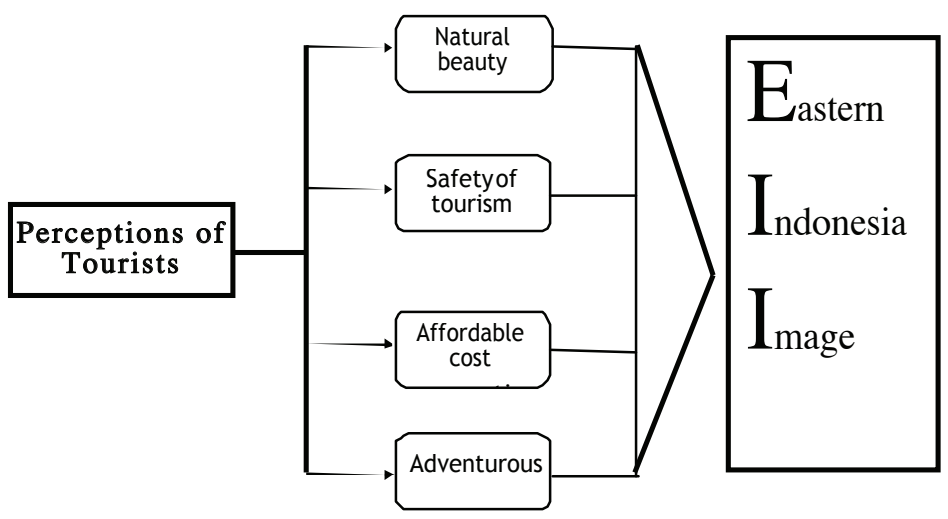

Figure 1. Conceptual Framework

Furthermore, the researchers need to reveal how the foreign tourists' perceptions of Bali influence their perception of Eastern Indonesia. By investigating them, at the end of this research, the researchers can provide useful information to plan a proper marketing strategy to develop tourist attractions in EasternIndonesia.

Zikmund, et al., (2011) stated that qualitative research is one of the most popular research approaches that is used in marketing and social research. Indeed, this type of method is designed to help the researchers to understand people's motivations, reasons, actions, and the context for their beliefs and actions in an in-depth way (Myers, 1997). For these reasons, a qualitative research method is considered as the most appropriate method to address the research objective in 'Understanding tourists' perceptions of Eastern Indonesia".

The interview questions followed the classification devised by Patton (1990) which suggests incorporation of questions on experience/behaviour, opinion/value feelings, knowledge, sensory experience and lastly demographic/background in an attempt to understanding their perceptions. Moreover, the researchers use focus groups as a mean of conducting this research project. Focus groups enable the participants to share their true feelings, anxieties, as well as the depth of their belief in their own words (Zikmund, 2011). Further, the focus group can provide alternative interpretations of findings that may not be able to gain by using traditional quantitative methods (Vaughn, et al., (1996). The data that the researchers collect in focus group can offer preliminary insights to hidden marketing phenomena (Hair \&e Lukas, 2008).

Beside, a purposive sampling will use to identify the participants of this research project. The participant will be limited to those who met the screening criteria of:

1) a person who identified as a foreign tourist to Indonesia and being over the age of 18 at the time the focus group interviews were conducted.

2) a person who had knowledge about Indonesia, particularly Bali.

3) a person who had experienced travelled to Bali and a person who had not visited Bali in the past.

However, there is no restriction in terms 
of demographics involved in this research project. The sampling method is illustrated in Figure 2.

In this research, data collection technique is focus group that consist of two groups. The first focus group made-up of five participants who have never been to Bali, Indonesia. While the second group consist of those people who have visited Bali, Indonesia. Each group consists of five people. The focus group last for 60 minutes up to 90 minutes for each group and there is a break in between for refreshments. Participants also informed that the focus groups location is in the Hub Central, The University of Adelaide, Australia. A public yet comfortable space chosen by the researchers to ensure that the process of the focus groups interview could be running properly. The researchers acted as the moderator in the focus group interviews. In addition, a discussion during the focus group sessions was audiotaped after agreed by participants. The video recording help the researchers to easily identify the behaviour of participants through their expressions and body language during the focus group sessions. After the data collection process finish, the researchers transcribe the audio- taped for analysis. To analyse the collected data, the researchers will use a thematic analysis method. Thematic analysis is one of the most common design of data analysis in qualitative method and identifies, analyses and reports themes within the data to find a meaning (Braun \& Clarke 2006; Flick 2014). The primary data collected will use a thematic analysis.

\section{RFSUITS}

This study interviewed International tourists in two categories, first is a group of people who have experienced to travel to Indonesia and second is a group of people who have never been to Indonesia. There are nine participants who contributed in this research focus groups interview. Group 1 involve foreign tourists who have never been to Indonesia and Group 2 includes people who have been to Indonesia. The research participants came from different background nationalities: Arabian, Australian, Bangladeshi, and Chinese. In Group 1, two participants are Chinese, one participant is Bangladeshi, and another two-participant is Saudi Arabian. This group consist of three males and two females. Meanwhile, in Group 2 all participants are Australian, three males and one female. All

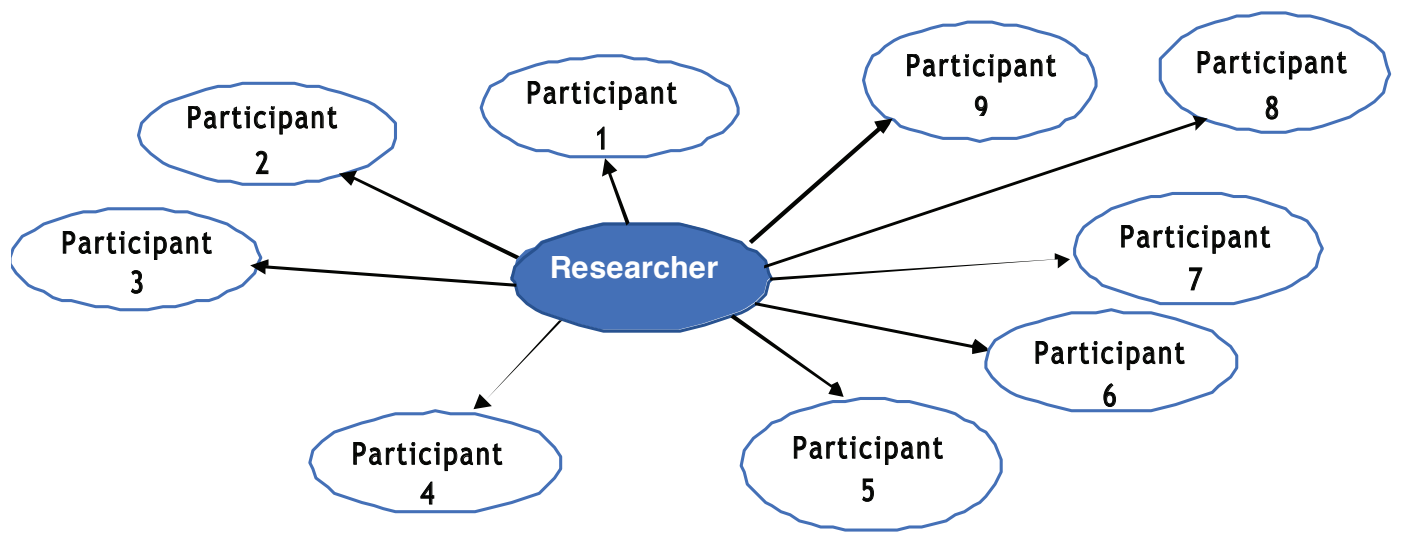

Figure 2. Purposive Sampling Method 
participants involved in this research were students (undergraduate and postgraduate students). The range of the participant ages for focus group 1 are between 25 and 29 years old. Whereas, focus group 2 consist of people in age 21-30. Eight out of nine participants identified as a single and one participant prefer not to mention his marital status. Further, the participants will mention as Participant 1 to Participant 9 in data analysis discussion. Participant 1 to participant 5 were in group 1 then participant 6 to participant 9 were in group 2.

\section{Research question 1:}

To what extent, do foreign tourists know about Eastern Indonesia?

Initially, participants in both group were asked about their general knowledge of Indonesia. Not surprisingly, all participants in group $1 \mathrm{knew}$ about Bali. It is mentioned in the beginning of the introduction where most foreigners only recognised Indonesia as Bali. In general, there is not much information that came up from the participants' responses. However, most of the participants in group 1 noticed about Indonesia's weather i.e., they can recognise Indonesia as a tropical country. Although participant 3 and 4 acknowledged that they knew Jakarta in Indonesia, they did not mentioned Jakarta as a capital city of the Republic Indonesia and did not have any idea which part in Indonesia that Jakarta is located. It indicates these participants are not sure whether Jakarta is a capital of Republic Indonesia or not. On the other hand, all participants in Group 2 have a broad knowledge about some places in Indonesia. In fact, they understand some characteristics of some cities in Indonesia. Four participants were mentioned some places that they have been to, for example: some places in Sumatera Island, in Java Island, in Nusa Tengfara Island, in Sulawesi Island.

In terms of general knowledge, participants in group 1 only have an exposure about Indonesia from what they heard from their friends and families. Apparently, the image of Indonesia is limited to Jakarta, Bali and the weather in Indonesia. Meanwhile, participants in group 2 which consists of people who have experiences of travelling in some places in Indonesia, including Eastern Indonesia present a comprehensive knowledge of Indonesia. Importantly, this study reveal an idea from participants in group 2 where all of them agreed that there is a misconception about Indonesia. Then participant 7 clearly added that there are two big misperceptions of Indonesia. Most participants knew Indonesia as a country since a long time ago as two participants in sroup 2 knew about Indonesia from the Geography class. Although he seemed not sure, when he first time knew about Indonesia, he can remember that Indonesia was mentioned in the geography class. This thought has a similarity with participant 4 in group 1 where she confirmed that she heard about Indonesia when she was in the early school at the geography class.

In addition, participants imagined that there are other countries which have similar characteristics with Indonesia, namely, Malaysia, Singapore, Thailand, and Cambodia in which they compared it based on their knowledge related to the weather and food. Normally, the participants obtained information from word-ofmouth. In this sense, cultural distance and environmental distance seems to affect non-visitor images.

The comparisons evident in the data differed 
according to whether non-visitors have experienced visited Indonesia or not. Nonvisitors from China compared the imagined environment to that of other country, such as Thailand and Malaysia. The assertion in perception is based on comparisons with the other country that the participant have visited but have a similarity with Indonesia. Massey (2007) mentioned that individuals use the background information that they have about the world in general to form their perceptions.

\section{Research question Z:}

What are the determinant factors that influence International tourists' willingness to travel abroad, particularly Eastern Indonesia?

In order to observe tourist's behaviour, we need to further investigate their travel motivation. A good motivational profile of visitors should be of assistance in understanding how well the destination characteristics satisfy the traveller's needs. Participants were asked about their thoughts to take into consideration the most important things when they decide to travel abroad. In this part, the researchers are trying to understand motivations regarding the experiences of tourists after visiting the destination and the motivations for the trips of tourists by non-visitors.

Three of the participants in group 2 mentioned safety in their top three lists the most important factors that they first consider to travel abroad. In fact, two of them put safety in the first list, whereas others stated that cost is the most important factors to consider. However, all of the participants have cost in their list; most of them put cost in the second list. Another thing that the participants will consider most is the natural world
The natural perceptions stick in their mind when imagining the destination that they will travel to. It is quite related to the participants' idea, which mention adventure because it normally can be found in the beautiful natural places. Beside, food is found as one of the factors that the participants would like to explore when visiting a destination. In contrast to most opinions from other participants, according to participant 1 , visa restriction is more important for him. It is true that some of these people were experiencing constraints to travel to a certain place due to the visa restriction, for example, Bangladesh.

In comparison with the responses from participants in group 1, most participants in group 2 have different ideas. Despite the positive image of the destination, some negative images may appear to influence the tourists' intention to visit certain place. The language barrier is apparently the most noticeable factors for participants in group 2. According to the experiences of Participant 8, at that time he visited Labuan Bajo, he could not find someone who does speak English to help him and his family during their trip. This concern was also emphasized from the previous research about the cultural distance. Language barrier is becoming something that significantly will influence the tourist intention to visit a destination. Another expression was mentioned from participants in group 2 as they are seeking particular holiday experiences. One of the participants in Group 2 revealed her desire to visit a particular place for a sport tourism purpose. Interestingly, four participants in group 2 showed a similar thought when they expressed their preference to visit a place where there is not many tourists visiting in that destination. From this perspective, it could be understood that 
these three participants were looking for a specific place to visit and avoiding to visit some common, crowded and noisy places. Meanwhile, participant 6 illustrated his idea by providing examples when he visited one of the memorable places in Sumatera Island.

Moreover, from the results of participant perspectives, seven participants from both groups agree that natural tourism is the most attractive tourism compared to other sort of tourisms, such as history and culinary tourism. One participant from Group 1 firmly stated that he needed relaxation during his holiday time and preferred to stay in the hotel while enjoying the best view from the hotel.

Interestingly, a significant difference appears between the participants who have never been to Indonesia and those participants who have been to Indonesia. Participants in Group 1 tend to put safety and cost at the top of their list as the most considered factors to influence them to travel abroad. One participant from Group 1 was very concerned about the safety issue since he had a bad experience during his travel abroad as they do not know about dangerous areas or local situations in which they might be very vulnerable to violent crimes.

Furthermore, participants were asked about their preference when seeking information about the destination. Most participants in both groups were looking on the internet for information, research, itineraries and booking trips. The internet gives every tourism operator and destination, regardless of size or resources, a prospect to engage the traveller (Goeldner \&e Ritchie, 2012). One of the best way to get visitors online is to use offline medianewspapers, magazine, brochures, and television to drive visitors to your Web site. In addition, travellers also post their experiences about places they visit, stay, enjoy, and eat using Blogs. By monitoring sites that contain reviews and comments about an organization, one can immediately address any issues.

\section{Research question 3:}

How do foreign tourists perceive Eastern Indonesia based on their experiences?

The perceptions of tourists depend largely on the important factors of destination reputation, quality of the services, and the adequate level of infrastructure. Investigation of participant perceptions on different group results in the image of Eastern Indonesia. All participants generally have a positive image about Eastern Indonesia according to their own experiences. Initially, participants in Group 2 suggest that most Australian recognised Bali as a party Island. The "Party Island" term, however, is subjective. It might be implied as a positive image if the foreign tourists found a pleasure. However, a negative image might follow that term if the foreign tourists feel uncomfortable with the effect on the image of the destination as a party island. In regards to the other places in Eastern Indonesia, most participants acknowledged some places give them pleasure. They found that some places in Eastern Indonesia bring some new experiences and unforgettable moment.

\section{Research question 4:}

How do foreign tourists perceive Eastern Indonesia based on what they heard from others (Friends, Families, Relatives, and Online sources)?

In comparison with participants in Group 2 experiences, this part will describe how 
perceptions form differently compared to the references that participants in Group 1 obtained. In response, a tourist perception can describe the importance of the promotion role in order to recognise the destination competitive value. In the focus group interview, the participant motivation in Group 1 was investigated. Some motives can be identified; the researchers argued that there were some motives that influence participant perceptions about Eastern Indonesia or Indonesia in general. All participants in Group 1 build and develop their perception based on some references, such as online media, friends, and family. Overall, all participants in Group 1 put friends and families as the main sources in obtaining information about Eastern Indonesia. The experiences from their friends and families stick in their mind and time to time they develop the perceptions by following their curiosity. Further, the participants also build their expectation in terms of infrastructure and superstructure of Eastern Indonesia. The infrastructure of tourism destination is yet another dimension that has not been put in place mainly to serve tourism. Such basic things as roads and communication network are the components of the infrastructure that important to visitors.

In contrast, a destination tourism superstructure includes those facilities that have been developed, especially to respond to the demands of visitors. The most obvious examples include hotels, restaurants, and major attractions. Technology not surprisingly is one of the most recent, and still increasingly influential, dimensions of the built environment that is shaping the nature of both tourism products/services and travel experiences. Technology significantly influences the increasing number of arrivals of tourists. In relation to the participant responses, they expect to visit a place that has an adequate technology to support their trip. Some participants mentioned that they rely on the internet to find some information about place that they visit.

To sum up, participants do not visit a place with standard objective destination features but instead journey to a location where they select activities and holiday experiences from those on offer to suit their personal psychological and motivational profile (Goeldner \& Ritchie, 2012). Experiencing a new culture, language, and food is a powerful motivation and need of many travellers. The key findings reveal some ideas from the participants which those ideas lead to their perceptions of Eastern Indonesia. Participants in Group 1 still have a limited knowledge of Eastern Indonesia as a non-visitor. However, they have a common knowledge that shape their perception of Eastern Indonesia in general as a beauty place and worth visiting place and friendly people. In regards to the research problem, the participants in Group 1 knew Bali but they do not understand some places in Eastern Indonesia and in fact, they do not recognise that Bali is located in Eastern Indonesia. Compared to participants in Group 1, participants in Group 2 have a wellunderstanding of some places in Eastern Indonesia and have experienced travel to some places in Eastern Indonesia as well. The experiences of all participants in Group 2 results in their positive perceptions of Eastern Indonesia and they show a great willingness to revisit some places in Eastern Indonesia. They also intend to go to new places in Eastern Indonesia and have some expectations from their current perception of Eastern Indonesia as a beautiful place to visit apart from the obstacles that may encounter during their trip. 


\section{CONCLUSION}

This study explored the tourist perceptions of Eastern Indonesia with a comparison between non-visitor and visitor perceptions. The findings are based on participant responses in a set of two different focus group interviews. The nine participants come from different nationalities: two Chinese, two Arabian, One Bangladeshi, four Australian. Both groups viewed Eastern Indonesia as interesting places to visit.

Visitors are influenced by what they trust most and/or what they find most interesting (destination images of non-visitors). This study also reveals valuable thoughts from the non-visitor participants by identifying their perceptions based on their experiences travelled abroad. Those who have not visited a destination can be categorised as a potential visitor. The different perceptions of Eastern Indonesia form the destination images in different ways. The researchers found that the participants who have never been to Indonesia show a great willingness to travel to Bali and other places in Eastern Indonesia. By focusing on non-visitors, this study aimed to understand what exactly the foreign tourists perceive and expect of Indonesia. In addition, equally important, assessing the visitor perceptions reveal some ideas whether the tourists are satisfied with their journey in Indonesia, particularly in Eastern Indonesia or not. In fact, this research reveal some suggestions and expectations of the tourists for other kind of tourisms such as sporty and natural tourism.

Furthermore, this study makes an important contribution to the Eastern Indonesia image literature and this current study has a number of implications for understanding the image of Eastern Indonesia. Essentially, this research brings some implication for marketing practice. Promotional campaigns and advertising need to be more intense and more creative, for example, creating more movies and films to increase the country image. The marketing campaign should target people who have never visited a destination so that they can more easily construct images of the destination. As organic sources including word-of-mouth are significant, so also, social media strategies are important (Zarrella, 2009). The web sites are likely to influence the destination images. This research reveal how non-visitors imagine places that they know even less about. It is true that the destination image significantly influences the tourist intention to visit Eastern Indonesia. Therefore, understanding tourist perceptions is important to develop a positive image. Finally, the researchers hope that this study can bring some benefits for the readers.. 


\section{RFFERENCES}

Baloglu, S. and McCleary, K.W., 1999. A model of destination image formation. Annals of tourism research, 26(4), pp.868-89\%.

Braun, V. and Clarke, V. (2006) Using thematic analysis in psychology. Qualitative Research in Psychology, 3 (2). pp. 77-101. 2008.

Cherifi, B., Smith, A., Maitland, R. and Stevenson, N., 2014. Destination images of non- visitors. Annals of Tourism Research, 49, pp.190-202.

Embacher, J. and Buttle, F., 1989. A repertory grid analysis of Austria's image as a summer vacation destination. Journal of Travel Research, $27(3)$, pp.3-7.

Flick, U., 2014. An introduction to qualitative research. Sage.

Gartner, William C. (1993). "Image Formation Process." Journal of Travel and Tourism Marketing.

Goeldner, C.R. and Ritchie, J.B., 2012. Tourism principles, practices, philosophies $12^{\text {th }}$ Edition. John Wiley \& Sons.

Hair, J.F., Lukas, B.A., Miller, K.E., Bush, R.P. and Ortinau, D.J., 2008. Marketing research. North Ryde.

Ivanov, S.H., 2010. German Students' Perceptions of Bulgaria as a Tourist Destination- A Molecular Approach to Destination Image Assessment.

Myers, Michael. (1997). Qualitative Research in Information Systems. MIS Quarterly. 21. $10.2307 / 249422$.

Nadeau, J., Heslop, L., O'Reilly, N. and Luk, P., 2008. Destination in a country image context. Annals of tourism Research, 35(1), pp.84-106.

Patton, M.Q., 1990. Qualitative evaluation and research methods. SAGE Publications, inc.

Shamsuddoha, M., Hossain, M.A., Shahriar, S. and Chakraborty, T., 2008. Development of Tourism Industry in Bangladesh.

Trading Economics 2018, Indonesia Tourist Arrivals, viewed 1 March 2018, <https:// tradingeconomics.com/indonesia/tourist-arrivals>.

Urbonavicius, S., Dikcius, V. and Navickaite, S., 2011. Country image and product evaluations: Impact of a personal contact with a country. Engineering economics, ఒ2(Z).

Vaughn, S., Schumm, J.S., and Sinagub, J.M. 1996. Focus Group Interviews in Education and Psychology. Sage.

World Tourism Organization UNWTO 2018, World tourism statistics and rankings, Compendium of Tourism Statistics, viewed 16 March 2018, <www2.unwto.org/content/compendiumtourism-statistics>.

Zarrella, D., 2009. The social media marketing book. "O’Reilly Media, Inc.”.

Zikmund, W., Ward, S., Lowe, B., Winzar, H. and Babin, B., 2011. Marketing Research: Second Asia-Pacific Edition. South Melbourne: Cencage Learning. p.65. 


\section{APPENDIX}

\section{Interview transcript}

\section{Research question 1: To what extent, do foreign} tourist know about Fastern Indonesia?

1) General knowledge about Indonesia

Initially, participants in both group were asked about their general knowledge of Indonesia. Not surprisingly, all participants in group $1 \mathrm{knew}$ about Bali. It is mentioned in the beginning of the introduction where most foreigners only recognised Indonesia as Bali. In general, there is not much information that came up from the participants" responses. Howrever, most of the participants in group 1 noticed about Indonesia"s weather i.e., they can recognise Indonesia as a tropical country. Participant 1 mentioned:

"What I know about Indonesia from my friends and family is only about Bali, many of my friends have chosen Bali as their honeymoon destination. Actually, for Indonesia, I just know about Bali, not even Jakarta and everything."

Yet, participant 3 and 4 acknowledged that they knew Jakarta in Indonesia. But, they did not mentioned Jakarta as a capital city of the Republic Indonesia and did not have any idea which part in Indonesia, that Jakarta is located. It means that, these participants are not sure whether Jakarta is a capital of Republic Indonesia or not. As Participant 3 stated that:

"For the places, I only know two places which are Bali and Jakarta."

On the other hand, all participants in Group 2 have a broad knowledge about some places in Indonesia. In fact, they understand some characteristics of some cities in Indonesia. Four participants were mentioned some places that they have been to, for example: some places in Sumatera Island, some places in Java Island, some places in Nusa Tenggara Island, some places in Sulawesi Island. Participant 6 has mentioned some cities that he visited:

"I guess I have been to the places that you guys mentioned, but in addition, Makassar, and few other cities in Sulawesi, like Pare-Pare, Palopo as well. And, then in Sumatera, I"ve been to Bengkulu, Padang, Medan, Bandar Lampung. And, plus the other places that others mentioned."

In terms of general knowledge, participants in sroup 1 only have an exposure about Indonesia from what they heard from their friends and families. Apparently, the image of Indonesia is limited to Jakarta, Bali and the weather in Indonesia. Meanwhile, participants in group 2 which consists of people who have experiences of travelling in some places in Indonesia, including Eastern Indonesia present a comprehensive knowledge of Indonesia.

Importantly, this study reveal an idea from participants in group 2 where all of them agreed that there is a misconception about Indonesia.

"I just gonna say something similar, like that is a big misconception that people have about Indonesia is very Islamic and very conservative. Someway is what it is. But perhaps, not as bad as what people think. I think when people think of tourism in Indonesia and even myself I think of Bali. I just think of Bali. I don"t necessarily think of anything other than people in Australia think of, like Java or Sumatera or Eastern Indonesia. But, in tourism context, I just know Bali or yeah also NTT."

*NTT is East Nusa Tenggara.

Then participant 7 clearly added that there are two big misperceptions of Indonesia.

"So, yeah that might be two main misperceptions, Indonesia as Islamic state and Indonesia is Bali."

Most participants knew Indonesia as a country since a long time ago. Two participants in group 2 knew about Indonesia from the Geography class. Participant 6 stated that: "My first exposure about Indonesia, probably, when I was in early school at the geography classes."

Although he seemed not really sure when he first time knew about Indonesia, he can remember that Indonesia was mentioned in the geography class. This thought has a similarity with participant 4 in group 1 where she confirmed that she heard about Indonesia when she was in the early school at the geography class.

The participants in group 1 knew Indonesia from their friends and families/relatives. Participants imagined that there are other countries which have similar characteristics with Indonesia, namely, Malaysia, Singapore, Thailand, and Cambodia. But, they compared it based on their knowledge related to the weather and food. Normally, the participants obtained information from word-of-mouth.

In this sense, cultural distance and environmental distance seems to affect non-visitor images. Specific traditions were also compared. As participant 1 reflected:

"I've been to Thailand but in Thailand as far if compared it with Indonesia, the weather is the closest thing. But the food and culture is totally different than Indonesia. But, if I think about all the perspective, I think Indonesia matches with my culture, Bangladesh because of the humidity, the tropical weather is humid and when it is in summer it is very sweaty and everything. In terms of food, Indonesian love spicy food, we also love spicy food. About the family bonding, in Bangladesh we have this too. There are a lot of similarity between Bangladesh and Indonesia."

The comparisons evident in the data differed according to whether non-visitors have experienced visited Indonesia or not. Non-visitors from China compared the imagined environment to that of other country, such as Thailand and Malaysia. Participant 4: "I probably imagine Bali or Indonesia more like Malaysia and Thailand". The assertion in perception is based on comparisons with the other country that the participant have visited but have a similarity with Indonesia. Massey (2007) mentioned that individuals use the background information that 
they have about the world in general to form their perceptions.

\section{Research question 2 : What are the determinant factors that influence International tourists' willingness to travel abroad?}

In order to observe tourist's behaviour, we need to further investigate their travel motivation. A good motivational profile of visitors should be of assistance in understanding how well the destination characteristics satisfy the traveler's needs. Participants were asked about their thoughts to take into consideration the most important things when they decide to travel abroad. In this part, the researcher is trying to understand motivations regarding the tourist experiences after visiting the destination and the motivations for the tourist's trip by non-visitors.

1) Factors that drive foreign tourists to their destination

Three of the participants in group 2 mentioned safety in their top three lists the most important factors that they first consider to travel abroad. In fact, two of them put safety in the first list. While others stated that cost is the most important factors to considered.

However, all of the participants have cost in their list; most of them put cost in the second list. Participant 2 stated as:

"First is safety because usually I carry specific gadgets. Second is cost or price. Third is Natural."

Another thing that the participants will consider most is the natural world. The natural perceptions stick in their mind when imagining the destination that they will travel to. It is quite related to the participants" idea which mention adventure. Because adventure normally can be found in the beautiful natural places. Also, food is found as one of the factors that the participants would like to explore when visiting a destination. For participant 3 , food is in the first place on the list.

"Well, for me, first maybe food. And second is price. Third, natural."

In contrast to most opinions from other participants, according to participant 1 , visa restriction is important for him.

"I would say first is Cost, then the Visa restriction because it"s quite difficult to get visa as a Bangladeshi, and third is adventure. Food, I eat everything."

It is true that some of these people were experiencing constraints to travel to a certain place due to the visa restriction. For example, Bangladesh.

In comparison with the participants' responses in group 1, most participants in group 2 have different ideas. Despite the positive image of the destination, some negative images may appear to influence the tourists" intention to visit certain place. The language barrier is apparently the most noticeable factors for participants in group 2. Participant 7 expresses her idea as:

"First thing that I will consider is language, like how many people in that country speak English and be able to communicate with people using English."

Participant 8 also supported this idea by stated: "Language is the most concern for me."

This statement is repeated in the following discussion with other participant, participant 8 emphasized this idea once more when he shared his experience when visiting one of the fascinating places in Eastern Indonesia, namely Labuan Bajo. The language barrier is a key feature of cultural distance.

"Money is not really concern if I am in Indonesia. But, the language is the most much concern for me, for example, when I took my mother and sister to Labuan Bajo (located in Nusa Tenggara Island), it had been very difficult for them, they struggle quite a bit, they don"t have the English skill to communicate, and my family don"t have any Indonesian skill as well. It"s quite difficult in terms of transport. If we don"t have an ability to speak with a foreign language. It would be something scary for me. Veryscary!"

Based on Participant 8's experience, at that time he visited Labuan Bajo, he cannot find someone who can speak English to help him and his family during their trip. This concern was also emphasized from the previous research about the cultural distance. Language barrier is becoming something that significantly will influence the tourist intention to visit a destination.

Another expression was mentioned from participants in group 2 . They are seeking particular holiday experiences. One of the participants in Group 2 revealed her desire to visit a particular place for a sport tourism purpose.

"I would say another thing on that when I think about Bali, I was think of Yoga teaching. They definitely have the number one place to go to Yoga training. Because, I do Yoga, lots of my friends teach there. Bali have an aspect for Yoga that need to market."

In addition, participant 7 expressed her thought as:

"I also love doing sporty activities when $I$ am traveling in a certain place, I wish I can come back to re-visit other places in Eastern Indonesia which is Nusa Teng'ara for hiking and rock climbing."

She is really keen in hiking and rock climbing. These desires generate the participants' image that influences her willingness to travel to a certain place.

Interestingly, four participants in group 2 showed a similar thought when they expressed their preference to visit a place where there is not many tourist visits in that destination. From this perspective, it can be understood that these three participants were looking for a specific place to visit and avoiding visiting common places which are crowded and noisy. Participant 6 illustrated his idea 
by providing examples when he visited one of the memorable places in Sumatera Island.

"I am so impressive when I went to the Banyak Islands because not many tourists go there. Bali and other places as I know near from Bali is quite crowded by tourists. I prefer to go to the places that no many tourists".

Moreover, based on the participants' result, seven participants from both groups agree that natural tourism is the most attractive tourism compare to other kind of tourism, such as history tourism and culinary tourism. One participant from Group I firmly stated that he needed relaxation during his holiday time and he prefer to stay in the hotel while enjoying the best view from the hotel.

Interestingly, there is a significant difference between the participants who have never been to Indonesia and those participants who have been to Indonesia. Participants in Group 1 tend to put safety and cost at the top of their list as the most considered factors to influence them to travel abroad.

One participant from Group 1 was very concerned about the safety issue since he had a bad experience during his travel abroad. Tourists must pay attention to safety. Tourists can be easy prey to criminals. They do not know about dangerous areas or local situations in which they might be very vulnerable to violent crimes.

\section{2) Information sources}

Participants were asked about their preference when seeking information about the destination. Most participants in both groups were looking to the internet for information, research, trip planning, and booking trips. The internet gives every tourism operator and destination, regardless of size or resources, a prospect to engage the traveler (Goeldner \& Ritchie, 2012).

"Well, I may search in internet first, I can find a lot information based on people's experience".

One of the best way to get visitors online is to use offline media-newspapers, magazine, brochures, and television-to drive visitors to your Web site. Also, your Web site should be search engine optimized (SEO). Blogs are used by travelers to post their experiences about places they visit, stay, enjoy, and eat. By monitoring sites that contain reviews and comments about an organization, one can immediately address any issues.

Participant 8 share his thought as: "I go Wikipedia, start scroll. It will give you in-depth more background. Also, then go to the website or blogs. And, find lots of idea from there. But, if I know somebody where I am going then generally I would ask to them. Like ask whether they say yes or not for the places that I want to visit."

And this is supported by participant '\%'s statement: "I actually probably look up thing in the internet the most, as the first time I went to Indonesia for the exchange, I don't speak any Bahasa. Wonderful Indonesia and Lonely Planet. Be talking with
Indonesian friends, Indonesia students in Adelaide. I would like to visit different places".

In comparison, participant 9 included a friend: he preferred to ask a local friend in the destination.

"For me, it would be a combine approach, like I will try to get as much information as possible. Especially, search something that I would like to do. The best what to do in Indonesia is probably asking for local friends and ask for the unique places. You can also use Indonesian website, the one with Indonesian tourists, like in Bahasa. Or, go to the lonely planet. So, that's what I look up".

\section{Research question 3: How do foreign tourists perceive Eastern Indonesia based on their experiences?}

Tourists' perceptions depend to a great extent on the important factors of destination reputation, quality of the services, and the adequate level of infrastructure. Investigation of participants' perceptions on different group result in the image of Eastern Indonesia.

1) Foreign tourists' perceptions about Eastern Indonesia based on their experience In general, all participants have a positive image about Eastern Indonesia based on their own experiences. Initially, participants in Group 2 suggest that most Australian recognised Bali as a party Island. The "Party Island" term, however, is subjective. It might be implied as a positive image if the foreign tourists found a pleasure. Howrever, a negative image might follow that term if the foreign tourists feel uncomfortable with the effect on the image of the destination as a party island.

In regards to the other places in Eastern Indonesia, most participants acknowledged some places give them pleasure. They found that some places in Eastern Indonesia bring some new experiences and unforgettable moment. When participant in Group 2 asked about their experiences in Eastern Indonesia, participant 8 stated as:

"When I was in North Sulawesi, it's very nice. But, the experience in Bali with the view of Mount Agung is such a beautiful thing. I think it"s hard to pinpoint like one cause they're all had aspect just beautiful between each other. Gili Meno in Lombok, Nusa Tenggara Timur is also bringan unforgettable moment."

\section{Research question 4: How do foreign tourists perceive Eastern Indonesia based on what they heard from others (Friends, Families, Relatives, and Online sources)?}

In comparison with participants in Group 2 experiences, this part will describe how perceptions form differently compared to the references that participants in Group 1 obtained. In response, a tourists' perception can describe the importance of the promotion role in order to recognise the destination's competitive value.

1) International tourists' perceptions about Eastern Indonesia based on what they heard

In the focus group interview, the participants 
motivation in Group 1 were investigated. Some motives can be identified; the researchers argued that there were some motives that influence participants' perceptions about Eastern Indonesia or Indonesia in general. All participants in Group 1 build and develop their perception based on some references, such as: online media, friends, and family.

Overall, all participants in Group 1 put friends and families as the main sources in obtaining information about Eastern Indonesia. The experiences from their friends and families stick in their mind and time to time they develop the perceptions by following their curiosity. Participant 2 describe it as below:

"Friends first, they gave me lot of information. After that, I go to google and find any extra information. Be aware enough. Actually, I don't ask friend who visit but I ask friend who live there".

Further, the participants also build their expectation in terms of infrastructure and superstructure of Eastern Indonesia. The infrastructure of tourism destination is yet another dimension that has not been put in place mainly to serve tourism. Such basic things as roads and communication network are the components of the infrastructure that important to visitors.
In contrast, a destinations' tourism superstructure includes those facilities that have been developed, especially to respond to the demands of visitors. The most obvious examples include hotels, restaurants, and major attractions.

Technology is one of the most recent, and still increasingly influential, dimensions of the built environment that is shaping the nature of both tourism products/services and travel experiences. Technology significantly influences the increasing number of tourists'arrivals. In relation to the participants' responses, they expect to visit a place that has an adequate technology to support their trip. Some participants mentioned that they rely on the internet to find some information about place that they visit.

To sum up, participants do not visit a place with standard objective destination features but instead journey to a location where they select activities and holiday experiences from those on offer to suit their personal psychological and motivational profile (Goeldner \& Ritchie, 2012). Experiencing a new culture, language, and food is a powerful motivation and need of many travelers. 